\title{
Prevalence of high, medium and low-risk medical conditions for pneumococcal vaccination in Catalonian middle-aged and older adults: a population-based study
}

O. Ochoa-Gondar ${ }^{1,2^{*}}$, I. Hospital ${ }^{1}$, A. Vila-Corcoles ${ }^{1,2}$, M. Aragon $^{3}$, M. Jariod ${ }^{4}$, C. de Diego ${ }^{1}$, E. Satue ${ }^{1}$ and EPIVAC Study Group

\begin{abstract}
Background: Updated population-based data on the frequency and distribution of risk factors for pneumococcal disease is scarce. This study investigated the prevalence of distinct comorbidities and underlying risk conditions related to an increasing risk of pneumococcal disease among Catalonian middle-aged and older adults.

Methods: Cross-sectional population-based study including 2,033,465 individuals aged 50 years or older registered at 01/01/2015 in the Catalonian Health Institute (Catalonia, Spain). The clinical research database of the Information System for the Development of Research in Primary Care (SIDIAP database) was used to identify high-risk (asplenia and/or immunocompromising conditions) and other increased-risk conditions (chronic pulmonary, cardiac or liver disease, diabetes mellitus, alcoholism and/or smoking) among study subjects.

Results: Globally, 980,310 (48.2\%) of the 2,033,465 study population had at least one risk condition of suffering pneumococcal disease (55.4\% in men vs $42.0 \%$ in women, $p<0.001 ; 41.7 \%$ in people $50-64$ years vs $54.7 \%$ in persons 65 years or older, $p<0.001)$. An amount of 176,600 individuals (8.7\%) had high-risk conditions (basically immunocompromising conditions). On the other hand, 803,710 persons (39.5\%) had one or more other risk conditions. In fact, 212,255 (10.4\%) had chronic pulmonary diseases, 248,377 (12.2\%) cardiac disease, 41,734 (2.1\%) liver disease, 341,535 (16.8\%) diabetes mellitus, 58,781 (2.9\%) alcoholism and 317,558 (15.6\%) were smokers.
\end{abstract}

Conclusion: In our setting, approximately $50 \%$ of overall persons 50 years or older may be considered at-risk population for pneumococcal disease (almost $10 \%$ have high-risk conditions and $40 \%$ have other risk conditions).

Keywords: Adults, Chronic illness, Pneumococcal disease, Prevalence, Streptococcus Pneumoniae, Risk factor

\section{Background}

Streptococcus pneumoniae is a Gram-positive bacterium that typically colonises the respiratory tract in humans, being the cause of serious illness and death in some individuals. After colonisation, possible outcomes are the clearance, the asymptomatic persistence (carrier state), or the bacterium can progress to the disease, causing mucosal infections (otitis, sinusitis, bronchitis and

\footnotetext{
* Correspondence: oochoa.tarte.ics@gencat.cat

'Primary Health Care Service "Camp de Tarragona", Institut Catala de la Salut, Rambla Nova 124, D, $1^{\circ} \mathrm{A}, 43001$ Tarragona, Spain

${ }^{2} U$ nitat de Suport a la Recerca of Tarragona, Institut Universitari d'Investigació en Atenció Primària Jordi Gol (IDIAP Jordi Gol), Tarragona, Spain

Full list of author information is available at the end of the article
}

nonbacteremic pneumonias) or resulting in invasive pneumococcal disease (IPD) such as bacteremic pneumonias, meningitis or sepsis. The outcome depends on interactions between factors related to the host, therapy and microorganism. [1, 2].

At present, pneumococcal infections remain a major cause of morbidity and mortality around the world, being one of the ten leading causes of death worldwide. [3] The risk for pneumococcal infection has been described as "high" in persons with immunosuppressive conditions, organ or bone marrow transplantation, immunosuppressive therapy and chronic renal failure or nephrotic syndrome as they have decreased responsiveness to polysaccharide 
antigens or an increased rate of decline in serum antibody concentrations. [4] Moreover, persons with functional or anatomic asplenia are at the highest risk for pneumococcal infection, because this condition leads to reduced clearance of encapsulated bacteria from the bloodstream. [1, 2, 4] Other adults at increased risk for developing pneumococcal infection or experiencing severe disease and complications include immunocompetent persons with chronic heart diseases, chronic pulmonary diseases, chronic liver diseases, diabetes mellitus, alcoholism and smoking. [5-8] Elderly persons (i.e, 65 years or older) are a major high-risk group for pneumococcal infections considering that certain degree of immunosenescence occurs in the elderly and, furthermore, the prevalence of chronic illnesses increases with age.

Several studies have investigated the prevalence of distinct risk conditions to suffer IPD among adult populations and have reported incidence of IPD among healthy adults as compared with those with underlying conditions. [8-11] Usually, the published data was calculated for distinct children age subgroups, adults 18-64 years and elderly persons, but generally there are no specific data disaggregated for distinct adult age subgroups (i.e, younger or middle-aged adults) despite the fact they may have distinct risks for pneumococcal disease. According to these studies, incidence of IPD is around 10 cases per 100,000 population-year among healthy adults over 18 years, with rates up to 50-times higher in some immunocompromised individuals (e.g, haematological cancer and/or HIV infection). $[8,11]$ According to published data, $39 \%$ of USA adults over 18 years have some risk condition for pneumococcal disease whereas this proportion ranges between 13 and 67\% in European studies. [8-11].

At present, two pneumococcal vaccines are available for use in adults: the "classical" 23-valent pneumococcal polysaccharide vaccine (PPV23) and the "new" 13-valent protein-polysaccharide conjugate vaccine (PCV13). The PPV23 was marketed in 1983 [4] whereas the PCV13 has only been available for use in adults since 2012. [12] From a public health point of view, the availability of two different vaccines for adults and the possibility of sequential vaccination with both vaccines is a key point to establish different vaccination strategies.

In Catalonia and Spain, since the 2000s, the PPV23 is recommended and publicly funded for all people aged 65 years or older (with or without risk conditions) as well as for those persons 18-64 years with certain underlying risk conditions such as asplenia, immunocompromising conditions, chronic pulmonary, cardiac, renal or liver disease, diabetes, alcoholism and smoking. [13, 14] The PCV13 is publicly funded only for "high" risk individuals (i.e, immunocompromised patients, anatomical or functional asplenia, cochlear implants and CSF leaks). $[13,14]$ The PCV13 is also prescribed by some doctor for some immunocompetent patients with other risk conditions (e.g. chronic bronchitis, asthma and/or cardiac disease) although it is not publicly funded in these individuals. [15].

In 2015, the reported pneumococcal vaccination coverage in Catalonia was 39\% among adults $\geq 50$ years-old ( $4.8 \%$ in $50-59$ years vs $35.5 \%$ in $60-69$ years vs $71.9 \%$ in $70-79$ years vs $79.5 \%$ in 80 years or older). [16] According to the most recent published data, incidence of IPD in Catalonia during the 2012-2014 period was 12.3 cases per 100,000 all-age population and year (40.9 in children under 2 years, 22.3 in children $2-4$ years, 3.9 in $5-19$ years, 7.4 in $20-64$ years and 31.8 in people $\geq 65$ years). [17].

As mentioned above, several studies have reported the prevalence of chronic illnesses and underlying conditions among hospitalised patients with IPD or pneumonia, [8-11] but there is limited population-based data reporting the prevalence of some conditions (especially low prevalence conditions) classically related with increasing risk for pneumococcal disease. Accurate prevalence data about risk conditions for pneumococcal disease is needed to calculate the true magnitude of at-risk groups and estimate the size of different target populations to implement distinct alternative antipneumococcal vaccination strategies currently available. [13-15, 18-20].

The present study investigated the prevalence of distinct comorbidities and underlying conditions related to increasing risk (high-, medium- and low-risk) for pneumococcal infections among Catalonian middle-aged and older adults. High-risk persons in the same population have been previously described elsewhere. [21].

\section{Methods}

This is a cross-sectional population-based study involving all individuals aged 50 years or older, who were registered in the Primary Health Care Centres (PHCCs) of the Catalonian Health Institute on January 1, $2015(N=2,033,465$ persons).

In Catalonia, a region in North Eastern Spain with seven million people, there are 358 PHCCs (comprised of family physicians, nurses and support staff) which are distributed by geographical area and are responsible for the health care of the population in their areas. The Catalonian Health Institute manages 274 PHCCs, serving a population of approximately five million people. Doctors and nurses systematically use electronic medical records to record medical diagnoses, underlying conditions, prescriptions, and other clinical patient management activities coded according to the International Classification of Diseases, 10th Revision (ICD-10).

The Catalonian Health Institute Information System for the Development of Research in Primary Care ("SIDIAP" database) compiles coded clinical information from the Electronic PHCC's records, [22] and it has been used as the data source for this report. Quality 
criteria for clinical data of the SIDIAP research database were reported in a validated comparison process. [23] The SIDIAP sample is representative of the general Catalonian population in terms of geography, age and sex distributions, according to the official census. [22].

The "SIDIAP" research database was used to identify chronic comorbidities and underlying medical conditions among study subjects, who were classified into three risk strata on the basis of immunocompromise degree and current recommendations for pneumococcal vaccination. $[4,13,14]$ Risk stratum 1 (highest-risk) included persons with anatomic or functional asplenia (ICD-10 codes: D57,D73, Q89), cochlear implants (Z96.2, Z45.3), CSF leaks (Z98.2), primary immunodeficiency (D80-D84), HIV infection (B20-B24), nephrotic syndrome (N04, N39.1), severe chronic renal failure (N18-N19 with glomerular filtration rate $\leq 30 \mathrm{ml} / \mathrm{min}$ ), bone marrow transplantation (Z94), solid organ or haematological neoplasia (C00 to C97) diagnosed within previous 5 years, long-term immunosuppressive medication and/or radiotherapy in the previous 12 months (coded according to specific SIDIAP codes). Risk stratum 2 (medium-risk) included immunocompetent patients without a level 1 condition but who had a history of chronic pulmonary/respiratory disease (including chronic bronchitis/emphysema [J41-J44], asthma [J45-J46] and/or other chronic pulmonary diseases [P27, E84, J47]), chronic cardiac disease (including congestive heart failure [I50], coronary artery disease [I20-I22, I25] and/or other chronic heart diseases [I05-I08, I11,I35I37,I42, I51.7]), chronic liver disease (including chronic viral hepatitis [B18], cirrhosis [K74] and/or alcoholic hepatitis [K70]), diabetes mellitus [E10-E14], alcoholism [F10, G31.2, G62.1, G72.1, I42.6, K29.2, K70] and smoking [F17]. Risk stratum 3 (lowest risk) included immunocompetent persons without level 1 or 2 conditions. We assumed that information in the SIDIAP database was complete, so a condition was considered absent if it was not recorded.

The statistical differences between prevalence for distinct risk conditions according to distinct population subgroups were evaluated using the Chi-squared tests, or Fisher's exact test as appropriate. Odds Ratios (ORs) with 95\% confidence intervals (CIs) were estimated to compare prevalence between gender and age groups. Statistical significance was set at $p<0.05$ (two-tailed). Data were analyzed using the SPSS version 18.0 (SPSS Inc., Chicago, IL, USA).

\section{Results}

Of the total 2,033,465 study population, 935,705 (46\%) were men and 1,097,760 (54\%) were women, being $1,021,648(50.2 \%)$ aged $50-64$ years and 1,011,817 (49.8\%) aged 65 years or older.

Globally, 980,310 (48.2\%) of the 2,033,465 study population had at least one risk condition to suffer pneumococcal disease $(55.4 \%$ in men vs $42.0 \%$ in women, $p<0.001 ; 41.7 \%$ in people $50-64$ years vs $54.7 \%$ in persons 65 years or older, $p<0.001$ ). Among the 50-64 years age subgroup, prevalence of persons with any high-risk condition (stratum 1) was $4.7 \%$ in men and 5.4\% in women, whereas prevalence of persons with any medium-risk condition (risk stratum 2) was $42.9 \%$ in men and $30.7 \%$ in women. Among the 65 years or older age subgroup, prevalence of persons with any high-risk condition (stratum 1) was $14.4 \%$ in men and $10.7 \%$ in women, whereas prevalence of persons with any medium-risk condition (risk stratum 2) was $50 \%$ in men and $36.7 \%$ in women (Figure 1).

Overall, 649,014 (31.9\%) of the total 2,033,465 study subjects had only one risk condition, 243,127 (12.0\%) had two risk conditions, 69,308 (3.4\% had three risk conditions and $18,861(0.9 \%)$ had four or more risk conditions.

If we consider those conditions associated with highest risk for pneumococcal infections (risk stratum 1), 3274 $(<0.1 \%)$ had primary immunodeficiency, 589 (0.2\%) HIV infection, $1480(0.1 \%)$ nephrotic syndrome, 15,468 (0.8\%) had severe renal failure, 5034 $(0.2 \%)$ had received bone marrow transplantation, 103,948 persons (5.1\%) had recent cancer diagnosis and 72,040 (3.5\%) received immunosuppressive treatment/radiotherapy in last 12 months. An amount of $294(<0.1 \%)$ had asplenia, $76(<0.1 \%)$ cochlear implants and $41(<0.1 \%)$ CSF leaks.

Considering that some persons had more than one high-risk condition, only 176,600 individuals $(8.7 \%)$ of the overall study population were classified in risk stratum 1 (9.2\% in men vs $8.2 \%$ in women, $p<0.001 ; 5.1 \%$ in persons $50-64$ years vs $12.3 \%$ in persons 65 years or older, $p<0.001)$.

If we consider the presence of other medical conditions related to an increased risk of pneumococcal infections classified in risk stratum 2, 212,255 persons (10.4\%) had chronic pulmonary/respiratory diseases, 248,377 persons (12.2\%) had chronic heart diseases, 41,734 (2.1\%) chronic

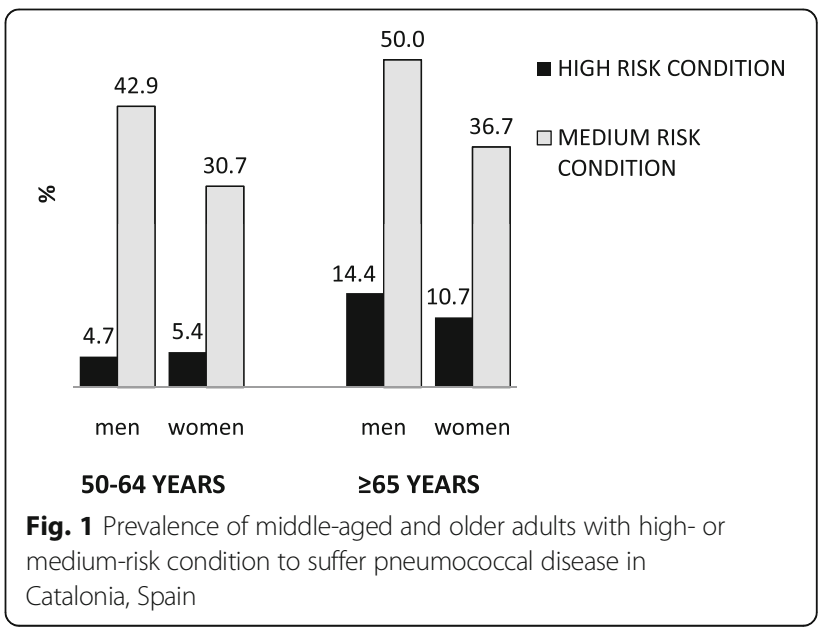


liver diseases, 341,535 (16.8\%) diabetes mellitus, 58,781 (2.9\%) alcoholism and 317,558 (15.6\%) were smokers.

Overall, 803,710 individuals (39.5\%) of the 2,033,465 study subjects were classified in risk stratum 2 because they had one of the above mentioned conditions but had no concomitantly conditions mentioned in risk stratum 1 (46.2\% in men vs $33.8 \%$ in women, $p<0.001 ; 36.7 \%$ in persons $50-64$ years vs $42.4 \%$ in persons 65 years or older, $p<0.001$ ).

A total of 1,053,155 persons (51.8\%) of the overall study population were classified as risk stratum 3 (lowest risk) because they did not present any risk condition mentioned in stratum 1 and/or 2. The prevalence for each one of the distinct risk factor/condition, according to gender and age strata, is shown in Tables 1 and 2, respectively.

\section{Discussion}

Pneumococcal disease is recognized as a major cause of morbidity and mortality around the world. [3] However, updated population-based data about the prevalence of some underlying medical conditions related to increasing risk of pneumococcal infections is limited. [8-11] We conducted a large population-based cross-sectional study assessing the prevalence of distinct risk underlying conditions to suffer pneumococcal diseases among
2,033,465 middle aged and older adults in a well defined geographical area in North-eastern Spain (Catalonia) with an overall population of seven million all-age inhabitants. The large size of the study population conforms an adequate basis to estimate population-based prevalence of these risk conditions in the Spanish population (which does not substantially differ from the Catalonian population). [22].

As main findings, approximately $10 \%(8.7 \%)$ of the overall study population have some underlying conditions related with highest risk for pneumococcal disease (basically immunocompromising conditions) and $40 \%$ (39.5\%) have other conditions related to increasing risk (basically chronic pulmonary or cardiac disease, diabetes and/or smoking). Therefore, almost $50 \%$ (48.2\%) of the overall population may be considered at-risk for pneumococcal infections in our study. In the present study, most underlying conditions were more common in men than in women. Substantial differences (more than two-times higher prevalence in men than in women) were observed for smoking, alcoholism and HIV infection. Only prevalence of primary immunodeficiency, immunosuppressive treatment, severe renal failure, CSF leaks and cochlear implant were more frequent in women. Recent literature suggests that pneumococcal vaccine effectiveness may be influenced by sex, [24] which underlines the importance

Table 1 Prevalence of major underlying conditions/risk factor for pneumococcal disease, according to gender, in people over 50 years in Catalonia, Spain

\begin{tabular}{|c|c|c|c|c|}
\hline & $\begin{array}{l}\text { MEN } \\
(N=935,705) \\
\mathrm{n}(\%)\end{array}$ & $\begin{array}{l}\text { WOMEN } \\
(N=1,097,760) \\
\mathrm{n}(\%)\end{array}$ & $\begin{array}{l}\text { ODDS RATIO (OR) } \\
\text { OR 95\%Cl }\end{array}$ & $\begin{array}{l}\text { OVERALL } \\
(\mathrm{N}=2,033,465) \\
\mathrm{n}(\%)\end{array}$ \\
\hline \multicolumn{5}{|l|}{ Immunocompromising conditions } \\
\hline Primary immunodeficiency & $237(<0.1)$ & $352(<0.1)$ & $0.79(0.67-0.93)$ & $589(<0.1)$ \\
\hline HIV infection & $2533(0.3)$ & $741(0.1)$ & $4.02(3.70-4.37)$ & $3274(0.2)$ \\
\hline Nephrotic syndrome & $900(0.1)$ & $580(0.1)$ & $1.82(1.64-2.02)$ & $1480(0.1)$ \\
\hline Severe renal failure $(G F R<30)$ & $6106(0.7)$ & $9362(0.9)$ & $0.76(0.74-0.79)$ & $15,468(0.8)$ \\
\hline Bone marrow trasplantation & $3096(0.3)$ & $1938(0.2)$ & $1.88(1.77-1.99)$ & $5034(0.2)$ \\
\hline Recent cancer & $55,475(5.9)$ & $48,473(4.4)$ & $1.36(1.35-1.38)$ & $103,948(5.1)$ \\
\hline Immunosuppressive medication/Radiotherapy & $29,408(3.1)$ & $42,632(3.9)$ & $0.80(0.79-0.82)$ & $72,040(3.5)$ \\
\hline \multicolumn{5}{|l|}{ Other high risk conditions } \\
\hline Asplenia & $141(<0.1)$ & $153(<0.1)$ & $1.08(0.85-1.37)$ & $294(<0.1)$ \\
\hline Cochlear implant & $27(<0.1)$ & $49(<0.1)$ & $0.65(0.39-1.07)$ & $76(<0.1)$ \\
\hline CSF leaks & $17(<0.1)$ & $24(<0.1)$ & $0.85(0.43-1.61)$ & $41(<0.1)$ \\
\hline Chronic respiratory disease & $115,432(12.3)$ & $96,823(8.8)$ & $1.45(1.44-1.47)$ & $212,255(10.4)$ \\
\hline Chronic heart disease & $135,426(14.5)$ & $112,951(10.3)$ & $1.48(1.46-1.49)$ & $248,377(12.2)$ \\
\hline Chronic liver disease & $23,290(2.5)$ & $18,444(1.7)$ & $1.49(1.46-1.52)$ & $41,734(2.1)$ \\
\hline Diabetes mellitus & $183,649(19.6)$ & $157,886(14.4)$ & $1.45(1.44-1.46)$ & $341,535(16.8)$ \\
\hline Alcoholism & $51,031(5.5)$ & $7750(0.7)$ & $8.11(7.92-8.31)$ & $58,781(2.9)$ \\
\hline Smoking & 194,865 (20.8) & $122,693(11.2)$ & $2.09(2.07-2.10)$ & $317,558(15.6)$ \\
\hline
\end{tabular}

Odds Ratios (ORs) were calculated for men as compared with women. Cl denotes confidence interval 
Table 2 Prevalence of major underlying conditions/risk factor for pneumococcal disease according to age strata

\begin{tabular}{|c|c|c|c|}
\hline & $\begin{array}{l}50-64 \text { yrs. } \\
(N=1,021,648) \\
n(\%)\end{array}$ & $\begin{array}{l}\geq 65 \text { yrs. } \\
(N=1,011,817) \\
N(\%)\end{array}$ & $\begin{array}{l}\text { ODDS RATIO } \\
\text { (OR) } \\
\text { OR 95\%Cl }\end{array}$ \\
\hline \multicolumn{4}{|l|}{ Immunocompromising conditions } \\
\hline Primary immunodeficiency & $295(<0.1)$ & $294(<0.1)$ & $1.01(0.85-1.19)$ \\
\hline HIV infection & $2825(0.3)$ & $449(<0.1)$ & $0.16(0.14-0.18)$ \\
\hline Nephrotic syndrome & $577(0.1)$ & $903(0.1)$ & $1.58(1.42-1.76)$ \\
\hline Severe renal failure $(G F R<30)$ & $1058(0.1)$ & $14,410(1.4)$ & $13.94(13.04-14.84)$ \\
\hline Bone marrow trasplantation & $2415(0.2)$ & $2619(0.3)$ & $1.10(1.04-1.16)$ \\
\hline Recent cancer & $30,339(3.0)$ & $73,609(7.3)$ & $2.56(2.53-2.68)$ \\
\hline Immunosuppressive medication/Radiotherapy & $22,319(2.2)$ & $49,721(4.9)$ & $2.31(2.28-2.35)$ \\
\hline \multicolumn{4}{|l|}{ Other high risk condition } \\
\hline Asplenia & $186(<0.1)$ & $108(<0.1)$ & $0.59(0.46-0.75)$ \\
\hline Cochlear implant & $23(<0.1)$ & $53(<0.1)$ & $2.33(1.39-3.91)$ \\
\hline CSF leaks & $11(<0.1)$ & $30(<0.1)$ & $2.75(1.33-5.83)$ \\
\hline Chronic respiratory disease & $67,987(6.7)$ & $144,268(14.3)$ & $2.33(2.31-2.36)$ \\
\hline Chronic heart disease & $49,362(4.8)$ & $199,015(19.7)$ & $4.82(4.77-4.87)$ \\
\hline Liver disease & $20,567(2.0)$ & $21,167(2.1)$ & $1.04(1.02-1.06)$ \\
\hline Diabetes mellitus & $100,855(9.9)$ & $240,680(23.8)$ & $2.85(2.83-2.87)$ \\
\hline Alcoholism & 36,808 (3.6) & $21,973(2.2)$ & $0.59(0.58-0.60)$ \\
\hline Smoking & $242,626(23.7)$ & $74,932(7.4)$ & $0.26(0.25-0.27)$ \\
\hline
\end{tabular}

Odds Ratios (ORs) were calculated for people $\geq 65$ years as compared with people $50-64$ years

$\mathrm{Cl}$ denotes confidence interval

of gender as a stratification factor to assess epidemiological data and vaccine's effectiveness.

Several studies have estimated the incidence of IPD among persons with high-risk conditions such as sicklecell anemia, HIV infection, chronic pulmonary diseases, cardiac diseases, alcoholism and/or smoking [4-11, 25, 26] According to systematic reviews, [4, 7] anatomic or functional asplenia, immunodeficiency and immunocompromising conditions are considered as major risk factors for pneumococcal infections. Nevertheless, considering the relatively small prevalence of these high-risk conditions, the majority of IPD cases occur among immunocompetent subjects who have other conditions that are also associated with an increased risk of pneumococcal infections (e.g. chronic pulmonary or heart disease, diabetes mellitus, smoking). [4, 8, 9, 25-27].

Most studies assessing the presence of risk conditions for pneumococcal diseases were hospital based studies involving hospitalized patients with IPD, but there is limited population-based data about the prevalence of some of these conditions. [8-11] The accurate knowledge of this data is important to determine the true size of potential target populations for distinct antipneumococcal vaccination strategies. According to current recommendations of the Advisory Committee on Immunization Practices (ACIP) of the Centers for Diseases Control and Prevention (CDC, Atlanta, Ga, USA), a sequential pneumococcal vaccination using PCV13 + PPV23 is recommended for persons aged 65 years or older (with or without underlying conditions) and persons 19-64 years with CSF leaks, cochlear implants, functional or anatomic asplenia and/or immunocompromising conditions (including congenital or acquired immunodeficiency, human immunodeficiency virus infection, chronic renal failure, nephrotic syndrome, leukemia, lymphoma, Hodgkin disease, generalized malignancy, iatrogenic immunosuppression due to treatment with immunosuppressive medication or radiation therapy, solid organ transplant and multiple myeloma). [19, 20] At present, ACIP/CDC (Atlanta, Ga, USA) recommends pneumococcal vaccination using exclusively PPV23 for immunocompetent persons 19-64 years with other comorbidities or risk conditions such as pulmonary or cardiac disease, diabetes mellitus, alcoholism and smoking, [18] however, other vaccination guidelines recommend using PCV13 in these subjects. [15, 28] In Catalonia and Spain, antipneumococcal vaccination recommendations for adult basically agree with the ACIP's recommendations except for people $\geq 65$ years (where sequential PCV13 + PPV23 is only recommended for immunocompromised subjects). [13, 14].

In the present study, risk strata were defined on the basis of immunocompromise degree and presence of other underlying conditions generally considered to establish pneumococcal vaccination recommendations. According 
to the current ACIP's recommendations (CDC, Atlanta, GA, USA), [18-20] all persons with any condition classified in our study as risk stratum 1 (basically immunocompromising conditions) should be vaccinated using a sequential PCV13 + PPV23 vaccination, whereas those persons classified as risk stratum 2 in our study (immunocompetent persons with other risk conditions such as chronic pulmonary or heart disease, diabetes, alcoholism or smoking) should receive PPV23 alone. Considering risk stratum 3 (immunocompetent persons without risk conditions), ACIP/CDC (Atlanta, GA, USA) recommends PCV13 + PPV23 for all people $\geq 65$ years (with or without risk conditions) [20] whereas other experts and guidelines (e.g, Catalonian Health Service) recommends only PPV23 if they do not have chronic illnesses or risk conditions. [13, 29].

Our data provides important information for policy makers in order to better determine the size of different target population considering distinct pneumococcal vaccination strategies (e.g., recommendation of PCV13 for all subjects with any risk condition or only for those with immunocompromising conditions; sequential vaccination with PCV13 + PPV23 for all people $>65$ years or only for those with certain risk conditions; etc). According to our data, approximately $5 \%$ of people $50-64$ years are at highest-risk for pneumococcal infections and consequently dual vaccination could be recommended. Within this $50-64$ years age subgroup, approximately $37 \%$ of persons have other risk conditions and therefore should be vaccinated with a unique pneumococcal vaccine (PPV23 according to current ACIP/CDC recommendations). [18] If we consider elderly people (i.e. 65 years or older), almost half of them (45.3\%) do not have underlying medical conditions requiring vaccination and they have only age criteria for increasing risk of pneumococcal infections. Thus a recommendation for dual vaccination based exclusively on age criteria $>65$ years (e.g. current ACIP/CDC recommendations) might be inefficient. [29].

In England, a study focused on adults who had received PPV23 estimated that $12.7 \%$ of population in 2009 had at least one of the risk conditions included in the recommendations for pneumococcal vaccination there (chronic pulmonary, cardiac, renal or liver disease, diabetes mellitus, immunocompromise, aspleny, cochlear implants and CSF leaks). [10] In Spain, a study conducted in Navarre estimated that almost $27 \%$ of the adult population had one or more risk condition of suffering pneumococcal disease. [30] In our setting, a prior cohort study involving 11,241 elderly individuals reported that $50.1 \%$ study subjects had no risk conditions for pneumococcal disease (apart from age), 29.2\% had one risk condition and $20.7 \%$ had two or more risk conditions. [31] Methodological differences in outcome definitions, together with age differences in the study populations, may explain differences in the reported prevalence.

Our study has several strengths. Study design was population-based and large enough to assess the prevalence of main underlying risk conditions related to invasive pneumococcal infections. In the study setting, similar to the rest of Spain, all inhabitants are covered by the National Health Service by a compulsory health assurance system, all inhabitants are assigned to a PHCC, medical assistance is free and most treatments are publicly funded; so a bias related to people who are not seeking care or have not been entered into the SIDIAP database is unlikely. As limitation, although the validity of clinical data source was previously checked, [23] information bias may have occurred if some comorbidities or underlying conditions were not recorded. We do not have available data about the prevalence of some high-risk conditions (e.g. solid organ transplantations); so the true size of the high-risk stratum for pneumococcal infections may have been slightly underestimated.

Considering the epidemiology of pneumococcal disease most studies report specific data on elderly people (i.e, 65 years or older) who experience substantial morbidity and mortality. However, data focused on younger and/or middle-aged adults is uncommon. In the present study, together with elderly people, we also included middle aged persons (i.e, persons aged 50-64 years) because they have a non-insignificant incidence of invasive pneumococcal disease (around 10 episodes per 100,000 population year in developed countries), [8-11] and this was the cut off point (50 years or older) to recommend PCV13 when it was initially licensed for use in adults. [12].

\section{Conclusions}

This large population-based study involving more than 2 million people investigating the prevalence of main risk conditions for pneumococcal infections among the general population 50 years or older in Catalonia, Spain, shows that approximately $50 \%$ of them may be considered at-risk population for pneumococcal disease. Of this $50 \%$ nearly $10 \%$ have high-risk conditions and $40 \%$ have medium-risk conditions. Updated epidemiological studies focused on distinct populations and geographical settings are necessary to know the prevalence of different risk conditions for pneumococcal disease, to clarify the true size of target populations for vaccination, and better allocate health care resources considering distinct vaccination strategies in adults.

\section{Acknowledgements}

We would like to acknowledge Angel Vila-Rovira and Timothy Bowring for their help in the production of this paper.

\section{Funding}

This work is supported, in part, by a grant from the "Fondo de Investigación Sanitaria" (FIS) of the "Instituto de Salud Carlos III" (call 2015) for the "Acción 
Estratégica en Salud 2013-2016 del Programa Estatal de Investigación Orientado a los Retos de la Sociedad", framing in the "Plan Estatal de Investigación Científica y Técnica y de Innovación 2013-2016"; code file PI15/01230, cofinanced by the European Union through the "Fondo Europeo de Desarrollo Regional" (FEDER). This work is also funded by a grant from the IDIAP Jordi Gol, Barcelona (grant SIDIAP 13/049).

\section{Availability of data and materials}

These data have been obtained from the Catalonian Health Institute Information System for the Development of Research in Primany Care (SIDIAP). Interested authors might obtain SIDIAP data (previous ethics and scientific approval by the ethics and clinical research committee of the Primary Care Research Institute Jordi Gol (IDIAP Jordi Gol)) addressing purposes to the Institution.

\section{Authors' contributions}

$\mathrm{OOG}, \mathrm{IH}, \mathrm{AVC}, \mathrm{CD}$ and ES designed the study, assessed outcomes, wrote and edited the paper; MA and MJ obtained the data; IH did statistical analyses; the two first listed authors contributed similarly to this work. All authors read and approved the final manuscript.

\section{Ethics approval and consent to participate}

The study was approved by the ethical committee of the Institution (ethic committee IDIAP Jordi Gol P14/134) and was conducted in accordance with the general principles for observational studies. Given this is a non-interventional study, an informed consent for all 2,033,465 study participants was not required. Data were anonymized and risk of identification was null.

\section{Consent for publication}

\author{
Not applicable.
}

\section{Competing interests}

The authors declare that they have no competing interests.

\section{Publisher's Note}

Springer Nature remains neutral with regard to jurisdictional claims in published maps and institutional affiliations.

\section{Author details}

"Primary Health Care Service "Camp de Tarragona", Institut Catala de la Salut, Rambla Nova 124, D, $1^{\circ} \mathrm{A}, 43001$ Tarragona, Spain. ${ }^{2}$ Unitat de Suport a la Recerca of Tarragona, Institut Universitari d'Investigació en Atenció Primària Jordi Gol (IDIAP Jordi Gol), Tarragona, Spain. ${ }^{3}$ Information System for the Improvement of Research in Primary Care (SIDIAP), Primary Care Research Institute Jordi Gol, Universitat Autonoma de Barcelona, Barcelona, Spain. ${ }^{4}$ Information Systems Department, Hospital Joan XXIII, Tarragona, Spain.

\section{Received: 10 February 2017 Accepted: 21 June 2017}

\section{Published online: 29 June 2017}

\section{References}

1. Ortqvist A, Hedlund J, Kalin M. Streptococcus Pneumoniae: epidemiology, risk factors, and clinical features. Semin Respir Crit Care Med. 2005;26:563-74.

2. Lynch JP, Zhanel GG. Streptococcus Pneumoniae: epidemiology and risk factors, evolution of antimicrobial resistance, and impact of vaccines. Curr Opin Pulm Med. 2010;16:217-25.

3. World Health Organization. Weekly epidemiological record. Pneumococcal vaccines. WHO position paper - 2012. Available from URL: http://www.who. int/wer/2012/wer8714.pdf?ua=1 [Accessed 8 Aug 2016].

4. Centers for Disease Control and Prevention. Prevention of pneumococcal disease: recommendations of the Advisory committee on Immunization Practices (ACIP). MMWR Morb Mortal Wkly Rep. 1997;46:1-24.

5. Dworkin MS, Ward JW, Hanson DL, Jones JL, Kaplan JE. Pneumococcal disease among human immunodeficiency virus-infected persons: incidence, risk factors, and impact of vaccination. Clin Infect Dis. 2001;32:794-800.

6. Nuorti JP, Butler JC, Farley MM, Harrison LH, McGeer A, Kolczak MS, et al. Cigarette smoking and invasive pneumococcal disease. N Engl J Med. 2000;342:681-9.

7. Schoenmakers MCJ, Hament JM, Fleer A, Aerts PC, van Dijk H, Kimpen JLL, et al. Risk factors for invasive pneumococcal disease. Revi Med Microbiol. 2002;13:29-36
8. Kyaw MH, Rose CE Jr, Fry AM, Singleton JA, Moore Z, Zell ER, et al. The influence of chronic illnesses on the incidence of invasive pneumococcal disease in adults. J Infect Dis. 2005;192:377-86.

9. Klemets P, Lyytikäinen O, Ruutu P, Ollgren J, Nuorti J. Invasive pneumococcal infections among persons with and without underlying medical conditions: implications for prevention strategies. BMC Infect Dis. 2008;8:96.

10. van Hoek AJ, Andrews N, Waight PA, Stowe J, Gates P, George R, et al. The effect of underlying clinical conditions on the risk of developing invasive pneumococcal disease in England. J Inf Secur. 2012;65:17-24.

11. Backhaus E, Berg S, Andersson R, Ockborn G, Malmström P, Dahl M, et al. Epidemiology of invasive pneumococcal infections: manifestations, incidence and case fatality rate correlated to age, gender and risk factors. BMC Infect Dis. 2016;16:367.

12. The Committee for Medicinal Products for Human Use. European Medicines Agency. Prevenar 13. Pneumoccal polysaccharide conjugate vaccine (13-valent, adsorbed). United Kingdom. 2011. Available from URL: Available from URL: http://www.ema.europa.eu/docs/en_GB/document_library/Summary_of_ opinion/human/001104/WC500112838.pdf [Accessed 22 Mar 2016].

13. Generalitat de Catalunya. Prevenció de la malaltia pneumocòccica en els adults i en els infants a partir dels 5 anys a Catalunya. Programa de vacunacions. Agència de Salut Pública de Catalunya. Gener de 2014. Available from URL: http://canalsalut.gencat.cat/web/.content/home_canal_ salut/professionals/temes_de_salut/vacunacions/documents/arxius/ prevencio_neumo_catalunya_adults.pdf. [Accessed 8 Aug 2016].

14. Grupo de trabajo vacunación frente a neumococo en grupos de riesgo 2015 de la Ponencia de Programas y Registro de Vacunaciones. Utilización de la vacuna frente a neumococo en grupos de riesgo. Comisión de Salud Pública del Consejo Interterritorial del Sistema Nacional de Salud. Ministry of Health, Social Services and Equality. 2015. Available from URL: http://www. msssi.gob.es/profesionales/saludPublica/prevPromocion/vacunaciones/docs/ Neumococo_Gruposriesgo.pdf. [Accessed 8 Aug 2016].

15. Picazo JJ, González-Romo F, García Rojas A, Peréz-Trallero E, Gil Gregorio P, de la Cámara R, et al. Consensus document on pneumococcal vaccination in adults with risk underlying clinical conditions. Rev Esp Quimioter. 2013;26:232-52.

16. Vila-Corcoles A, Ochoa-Gondar O, Hospital I, de Diego C, Satué E, Bladé J, et al. Pneumococcal vaccination coverages among low-, intermediate-, and high-risk adults in Catalonia. Hum Vaccin Immunother. 2016;12:2953-8.

17. Ciruela P, Izquierdo C, Broner S, Hernández S, Muñoz-Almagro C, Pallarés R, et al. Sistema de notificació microbiològica de Catalunya. Epidemiologia de la malaltia pneumocòccica invasiva a Catalunya. Informe 2012-2014. Available from URL: http://salutpublica.gencat.cat/ca/vigilancia_salut_ publica/sistemes-de-declaracio-epidemiologica/sistema-de-notificaciomicrobiologica-de-catalunya-snmc/. [Accessed 8 Sep 2016].

18. Centers for Disease Control and Prevention (CDC). Advisory Committee on Immunization Practices (ACIP). Updated recommendations for prevention of invasive pneumococcal disease among adults using the 23-Valent pneumococcal polysaccharide vaccine (PPSV23). MMWR. 2010;59(34):1102-6.

19. Centers for Disease Control and Prevention. Use of 13-valent pneumococcal conjugate vaccine and 23-valent pneumococcal polysaccharide vaccine for adults with immunocompromising conditions: recommendations of the Advisory committee on Immunization Practices (ACIP). MMWR Morb Mortal Wkly Rep. 2012;61:816-9.

20. Centers for Disease Control and Prevention. Use of 13-Valent pneumococcal conjugate vaccine and 23-Valent pneumococcal polysaccharide vaccine among adults aged $\geq 65$ years: recommendations of the Advisory committee on Immunization Practices (ACIP). MMWR Morb Mortal Wkly Rep. 2014;63:822-5.

21. Vila-Corcoles A, Hospital I, Ochoa-Gondar O, de Diego C, Satue E, Aragón M, et al. Prevalence of high-risk underlying conditions for pneumococcal disease among people over 50 years in Catalonia, Spain. Primary Health Care. 2016;6:234.

22. Information system for the development of research in primary care (SIDIAP data base). Available from URL: http://www.sidiap.org/ [Accessed Juny 8, 2016].

23. García-Gil MM, Hermosilla E, Prieto-Alhambra D, Fina F, Rosell M, Ramos R, et al. Construction and validation of a scoring system for the selection of high-quality data in a Spanish population primary care database (SIDIAP). Inform Prim Care. 2011;19:135-45.

24. Wiemken TL, Carrico RM, Klein SL, Jonsson CB, Peyrani P, Kelley RR, et al., CAPO Investigators. The effectiveness of the polysaccharide pneumococcal vaccine for the prevention of hospitalizations due to Streptococcus Pneumoniae community-acquired pneumonia in the elderly differs 
between the sexes: results from the community-acquired pneumonia organization (CAPO) international cohort study. Vaccine. 2014;32:2198-203.

25. Pastor P, Medley F, Murphy TV. Invasive pneumococcal disease in Dallas County, Texas: results from population-based surveillance in 1995. Clin Infect Dis. 1998;26:590-5.

26. Robinson KA, Baughman W, Rothrock G, Barrett NL, Pass M, Lexau C, et al. Epidemiology of invasive Streptococcus Pneumoniae infections in the United States, 1995-1998: opportunities for prevention in the conjugate vaccine era. JAMA. 2001;285:1729-35.

27. Vila-Corcoles A, Aguirre-Chavarria C, Ochoa-Gondar O, de Diego C, Rodriguez-Blanco T, Gomez F, et al. Influence of chronic illnesses and underlying risk conditions on the incidence of pneumococcal pneumonia in older adults. Infection. 2015;43:699-706.

28. Haut Conseil de la Santé Publique. Avis relative aux recommendations de la vaccination pour les adultes et les enfants âgés de plus de 2 ans à risque d'infection invasive à pneumocoque. 25 avril 2013. Available from URL: http://www.hcsp.fr/Explore.cgi/avisrapportsdomaine?clefr=355 [Accessed 2 Sep 2016].

29. Musher DM, Rodriguez-Barradas MB. Why the recent ACIP recommendations regarding conjugate pneumococcal vaccine in adults may be irrelevant. Hum Vaccin Immunother. 2016;12:331-5.

30. Torres de Mier MV, Masa J, Barricarte A. Estimación de población de grupos de riesgo (GR) en España. Comisión de Salud Pública del Consejo Interterritorial del Sistema Nacional de Salud. Ministry of Health, Social Services and Equality. 2015.[Spanish] Available from URL: http://www.msssi.gob.es/profesionales/ saludPublica/prevPromocion/vacunaciones/docs/Neumococo_Gruposriesgo.pdf. [Accessed 8 Aug 2016].

31. Vila Córcoles A, Ochoa Gondar O, Ansa Echeverría X, Bladé Creixenti J, Palacios Llamazares L, Fuentes Bellido CM. Coverage and association with clinical variables of antipneumococcal vaccination of the population over 65 years old in Tarragona-Valls. Rev Esp Salud Publica. 2005;79:645-54.

\section{Submit your next manuscript to BioMed Central and we will help you at every step:}

- We accept pre-submission inquiries

- Our selector tool helps you to find the most relevant journal

- We provide round the clock customer support

- Convenient online submission

- Thorough peer review

- Inclusion in PubMed and all major indexing services

- Maximum visibility for your research

Submit your manuscript at www.biomedcentral.com/submit

) Biomed Central 